\title{
Modelling the extreme precipitation event over Madeira Island on 20 February 2010
}

\author{
T. Luna ${ }^{1}$, A. Rocha ${ }^{2}$, A. C. Carvalho ${ }^{3}$, J. A. Ferreira ${ }^{2}$, and J. Sousa ${ }^{2}$ \\ ${ }^{1}$ IDAD The Institute for Environment and Development, Campus Universitario de Santiago 3810-193 Aveiro, Portugal \\ ${ }^{2}$ Department of Physics, CESAM, University of Aveiro, Campus Universitario de Santiago 3810-193 Aveiro, Portugal \\ ${ }^{3}$ CENSE, Departament of Science Environmental Engineering, Faculdade de Ciências e Tecnologia, Universidade Nova \\ de Lisboa, 2829-516 Caparica, Portugal
}

Received: 22 July 2010 - Revised: 24 May 2011 - Accepted: 13 June 2011 - Published: 15 September 2011

\begin{abstract}
In the morning of the 20 February of 2010 an extreme precipitation event occurred over Madeira Island. This event triggered several flash floods and mudslides in the southern parts of the island, resulting in 42 confirmed deaths, 100 injured, and at least 8 people still missing. These extreme weather conditions were associated to a weather frontal system moving northeastwards embedded in a low pressure area centered in the Azores archipelago. This storm was one in a series of such storms that affected Portugal, Spain, Morocco and the Canary islands causing flooding and strong winds. These storms were bolstered by an unusually strong sea surface temperature gradient across the Atlantic Ocean.

In this study, the WRF model is used to evaluate the intensity and predictability of this precipitation extreme event over the island. The synoptic/orographic nature of the precipitation is also evaluated, as well as the sensitivity of the model to horizontal resolution and cumulus parameterization. Orography was found to be the main factor explaining the occurrence, amplitude and phase of precipitation over the Island.
\end{abstract}

\section{Introduction}

Orography may play an important role in disturbing synoptic scale systems through an exchange of energy and momentum with the mesoscale. This may bring about smaller scale phenomena which, would be absent otherwise. These will depend on the presence and combination of factors such as atmospheric stability, direction of the main flow when a mountain is encountered, presence of water vapor and wind shear.

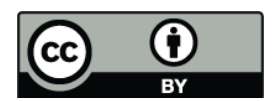

Correspondence to: T. Luna

(tiagoluna@ua.pt)
Examples of such orographically induced weather phenomena are related to mountain waves and vortices that may be associated or not with clouds and precipitation, frontal distortion across mountains, cold-air damming, track deflection of mid-latitude and tropical cyclones, coastally trapped disturbances, orographically induced rain and flash flooding, and orographically influenced storm tracks (Lin, 2007).

Orographic precipitation, also known as relief precipitation, is a result of very complex processes. It is generated by a forced upward movement of air upon encountering a physiographic upland (anabatic wind). A mass of moist air, forced to rise along the slope of a mountain high enough can reach saturation due to expanding and adiabatic cooling (Wallace and Hobbs, 1977). This adiabatic cooling of a rising moist air parcel may lower its temperature to its dew point, thus allowing for condensation of the water vapor contained within it and hence the formation of orographic clouds. If enough water vapor condenses into cloud droplets, these droplets may become large enough to fall to the ground as precipitation (Srinivasan et al., 2005).

Terrain-induced precipitation is a major factor to deal with, when forecasting local to mesoscale weather (Hohenegger et al., 2005). Orography can play a major role in the type, amount, intensity and duration of precipitation events (Srinivasan et al., 2005). Studies have showed that barrier width, slope steepness and updraft speed are major contributors for the optimal amount and intensity of orographic precipitation (Srinivasan et al., 2005). Computer model simulations for these factors showed that narrow barriers and steeper slopes produce stronger updraft speeds which, in turn, enhance orographic precipitation (Srinivasan et al., 2005).

Specifically over the Iberian Peninsula, Costa et al. (2010) have analysed the influence of orography on precipitation during a limited period in spring. Case study simulations were performed with and without orography in order to assess the effects of the mountains. Simulations showed

Published by Copernicus Publications on behalf of the European Geosciences Union. 
that orography is a key factor in determining the spatial distribution of precipitation over the Iberian Peninsula, with enhancements in the regions with mountain ranges and diminution or suppression over certain valleys, which is in line with previous work (Colle, 2004).

In this study we use a mesoscale numerical weather prediction model to simulate a precipitation extreme event which occurred in the morning of the 20 February 2010 over Madeira Island. This event was associated to a frontal system, embedded in a depression centered over the Azores archipelago, and moving to the northeast. The floods and mudslides triggered by this event had important social and economic consequences. More than 40 people died in the event and several houses were destroyed.

A previous work has already analyzed the ability of the NCEP (National Center for Environmental Prediction of the United States of America) ensemble Global Forecasting System (GFS) to forecast the same event (Grumm, 2010). Grumm's results show that the pattern associated to the heavy rainfall event over Madeira was well predicted and indicates the advantage of using high resolution models to predict local, heavy rain. Moreover, Grumm's study came to the conclusion that previous conditions and earlier rainfall may have contributed to the mud slides.

The advantage of using higher resolution simulations is related, amongst other factors, to the topographic characteristics of the island. Madeira Island is $55 \mathrm{~km}$ long with a maximum width of $22 \mathrm{~km}$ and rises, in the center, to Pico Ruivo, the highest point of the Island with $1861 \mathrm{~m}$.

The present work addresses the following questions, related to the forecast of the heavy rain event of the 20 February 2010, over Madeira Island.

1. Was the event predictable?

2. If yes:

How long before its occurrence?

With maximum precipitations amounts correct?

Without phase errors?

3. Was its origin synoptic or orographic?

4. What is the sensitivity of the simulations to higher horizontal resolution and cumulus parameterization?

\section{Methodology}

The meteorological model used in the present work is the Weather Research and Forecasting - Advance Research model (WRF-ARW) version 3.1 (Skamarock et al., 2008). The WRF model was driven by GFS forecasts (NCEP, 2003) for the period of interest. The GFS model has an approximated horizontal resolution of $0.5^{\circ} \times 0.5^{\circ}$ and the vertical domain extends from a surface pressure of $1000 \mathrm{hPa}$ to
$0.27 \mathrm{hPa}$ discretized in 64 vertical unequally-spaced levels, from which 15 levels are located below $800 \mathrm{hPa}$ and 24 levels above $100 \mathrm{hPa}$.

Two WRF nest configurations were applied to Madeira Island. One is that used in the forecasts shown at the Clim@UA ${ }^{1}$ site, which consists of two nested domains namely, a parent domain (D1) with a spatial coverage of $25 \mathrm{~km}$ horizontal resolution and a child domain (D2) with $5 \mathrm{~km}$ horizontal resolution. In the other configuration, a third domain (D3), with horizontal resolution of $1 \mathrm{~km}$, was nested into domain D2. The three domains are shown in Fig. 2.

Ferreira A.P. (2007) applied the WRF model to mainland Portugal, performed numerical experiments with several sets of physical parameterizations, and compared the results with observed data with the aim of finding the best combination of parameterizations. The set of parameterizations that (Ferreira A.P., 2007) was found to give the best results was used in the present study. Hence, the following schemes were used in all simulations: WRF Single-Moment 6-class scheme microphysics (Hong et al., 2006), Goddard shortwave radiation (Skamarock et al., 2008), Rapid Radiative Transfer Model (RRTM) longwave radiation model (Mlawer et al., 1997), the Eta similarity surface layer scheme (Skamarock et al., 2008), Mellor-Yamada-Janjic planetary boundary layer scheme (Janjic Z. I., 1990, 1996, 2002) and the Noah Land Surface Model (Chen and Dudhia., 2001). In terms of cumulus parameterization, the Grell-Devenyi ensemble scheme was used (Grell and Devenyi, 2002).

Table 1 shows a summary of the simulations performed during this study. These simulations may be divided into four groups. Each group is formed by several runs. The first group (A) is a single two-nested WRF run forced by the GFS $6 \mathrm{~h}$ analysis fields (RunAnal). The second group (B) consists of nine runs forced by GFS forecasts. The difference between these runs is the starting date/time (Run00, Run0, Run1, Run2, Run3, Run4, Run5, Run6 and RunPrev). A third group (C) is formed by two runs with three nested domains, both starting at the same time and using different cumulus parameterization schemes (Run7 and Run8). Finally, the fourth group (D) is formed by a single run, with three nested domains but with flattened island topography (TopoOff).

As mentioned above, the WRF model was forced under two distinct modes: (i) forced at the lateral boundaries with the analyzed fields every $6 \mathrm{~h}$; and (ii) forced at the lateral boundaries with the GFS forecast fields every $3 \mathrm{~h}$. All simulations started from an initial state derived from the analyzed fields at the starting hour of simulation. The following analysis was divided into three main parts. First we analyzed the ability of the GFS model to predict the general conditions that led to the precipitation event of the 20 February. Here, we computed and compared the temporal evolution of precipitable water averaged for the GFS analyses and forecasts,

\footnotetext{
${ }^{1}$ http://climetua.fis.ua.pt
} 
Table 1. WRF simulations. Cumulus parameterization used: 0 No cumulus, 3 Grell-Devenyi ensemble scheme (Grell and Devenyi, 2002)

\begin{tabular}{ccccc}
\hline $\begin{array}{c}\text { Simulation } \\
\text { Group }\end{array}$ & Run & $\begin{array}{c}\text { Start } \\
\text { Date }\end{array}$ & $\begin{array}{c}\text { Number of } \\
\text { Domains }\end{array}$ & $\begin{array}{c}\text { D3 Cu } \\
\text { parameterization }\end{array}$ \\
\hline A & RunAnal & 20 Feb 00:00 UTC & 2 & NA \\
\hline B & Run00 & 19 Feb 06:00 UTC & 2 & NA \\
& Run0 & 19 Feb 00:00 UTC & 2 & NA \\
& Run1 & 18 Feb 12:00 UTC & 2 & NA \\
& Run2 & 17 Feb 12:00 UTC & 2 & NA \\
& Run3 & 16 Feb 12:00 UTC & 2 & NA \\
& Run4 & 15 Feb 12:00 UTC & 2 & NA \\
& Run5 & 14 Feb 12:00 UTC & 2 & NA \\
& Run6 & 13 Feb 12:00 UTC & 2 & NA \\
& RunPrev & 20 Feb 00:00 UTC & 2 & NA \\
\hline C & Run7 & 20 Feb 00:00 UTC & 3 & 3 \\
\hline & Run8 & 20 Feb 00:00 UTC & 3 & 0 \\
\hline
\end{tabular}

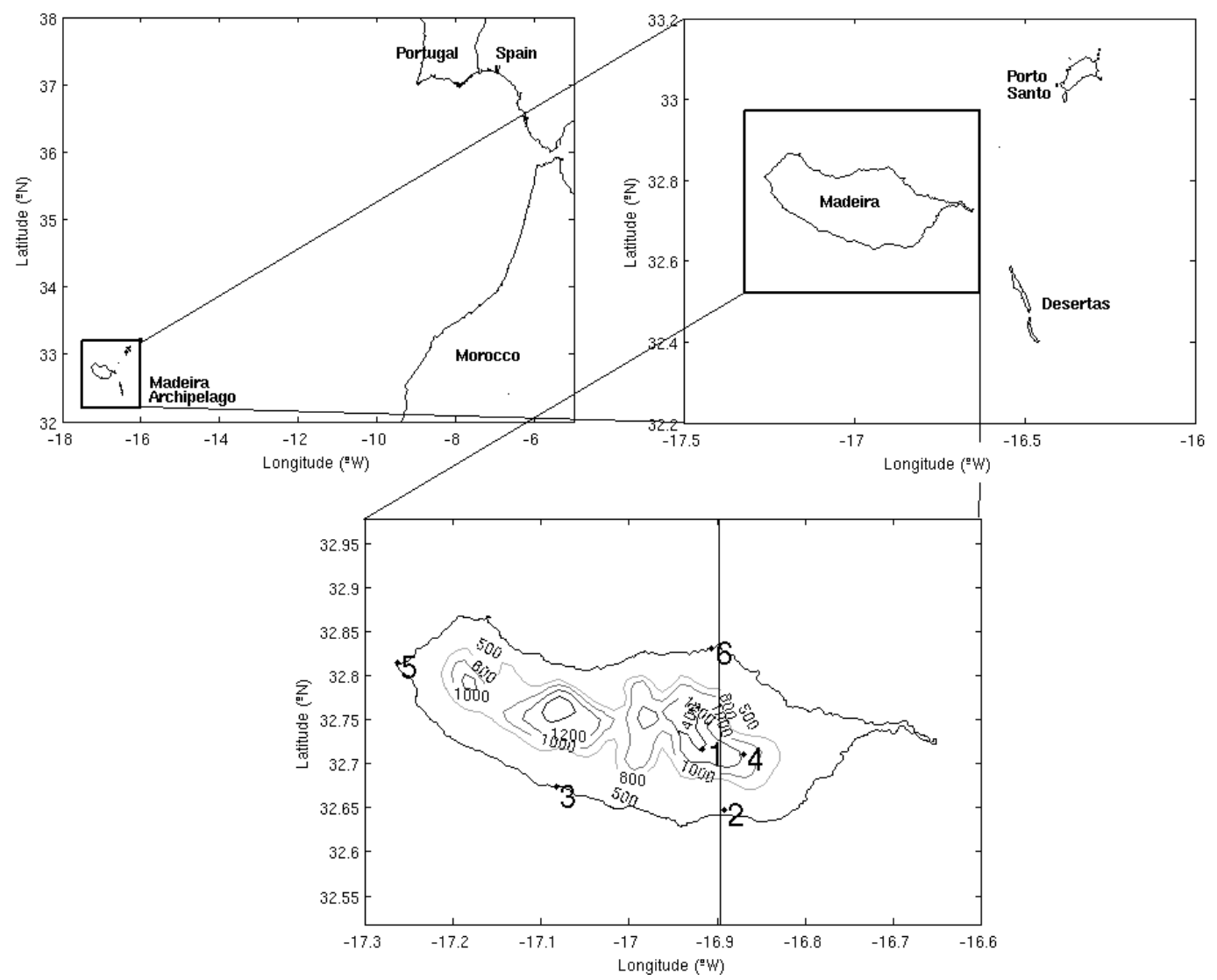

Fig. 1. Map of the Madeira archipelago location in the Atlantic Ocean, showing Madeira, Porto Santo and Desertas Islands. Madeira topography is shown with the location of weather stations used to evaluate the simulated precipitation described in Table 2 , as well the location of the cross section used in this work. 


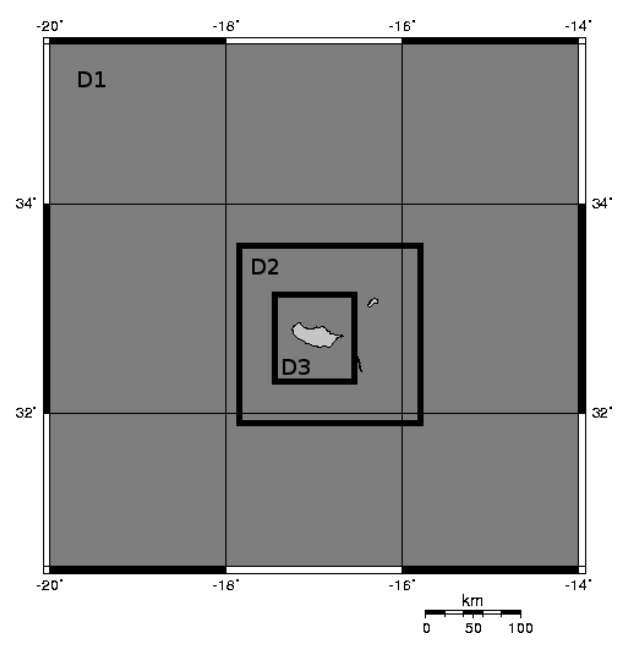

Fig. 2. WRF domains D1, D2 and D3 with horizontal resolutions of 25,5 and $1 \mathrm{~km}$, respectively.

as well as the area averaged absolute vorticity tendency at the $500 \mathrm{hPa}$ isobaric surface. As the GFS is a global model with a horizontal resolution of $0.5^{\circ}$, this calculation was performed for an area larger than the D1 WRF domain, but containing D1. One hoped that the comparison between GFS forecast and analysis precipitable water would reveal the quality of the initial and boundary conditions used in the WRF simulations. In the second part of the analysis we studied the precipitation event reproduced by several numerical experiments listed in Table 1. We looked at area-averages of daily precipitation for the 20 February in order to highlight the differences between the simulations. On the day of the rainfall event, Madeira Island was under the influence of a strong southerly flux of air with a high precipitable water content (Grumm, 2010). In order to evaluate the effect of topography in the overall precipitation distribution over the island, we computed the area-averaged precipitation for the entire island and for its northern and southern parts. For these computations, several landmasks were constructed over the WRF domains D2 and D3. The mask for the entire island is the one extracted from the output of the WRF model. For the northern and southern parts, the division was made by following the mountain ridge of the island. This analysis was complemented by studying the contribution of the highest parts of the island to the total precipitation amount on the entire island. To achieve this, we computed the area-averaged precipitation for heights lower than $800 \mathrm{~m}$, again for the entire island and for its northern and southern parts. The analysis ended with a more detailed study of simulated hourly precipitation and a comparison with observed hourly precipitation for certain locations.

Next, an analysis of the model skill was performed. In order to validate the simulated precipitations amounts, a total of six weather stations were considered. Five of these six stations are owned and operated by the Portuguese
Table 2. Weather Station information used to evaluate model skill. Data from 00:00 UTC 20 February to 00:00 of 21 February 2010.

\begin{tabular}{llccrr}
\hline Location & $\begin{array}{c}\text { Latitude } \\
\left({ }^{\circ}\right)\end{array}$ & $\begin{array}{c}\text { Longitude } \\
\left({ }^{\circ}\right)\end{array}$ & $\begin{array}{r}\text { Altitude } \\
(\mathrm{m})\end{array}$ & $\begin{array}{r}\text { with Number } \\
\text { of hours } \\
\text { precipitation } \\
\text { records }\end{array}$ \\
\hline 1 & Areeiro & 32.71 & -16.91 & 1610 & 18 \\
2 & Funchal & 32.64 & -16.89 & 58 & 24 \\
3 & Lugar de Baixo & 32.67 & -17.08 & 15 & 17 \\
4 & Meia Serra & 32.71 & -16.87 & 1202 & 24 \\
5 & Ponta do Pargo & 32.81 & -17.26 & 312 & 24 \\
6 & S. Jorge & 32.83 & -16.90 & 185 & 24 \\
\hline
\end{tabular}

Meteorological Institute ${ }^{2}$ (Areeiro, Funchal, Lugar de Baixo, Ponta do Pargo and S. Jorge). Meia Serra station is managed by a wastewater treatment plant near Areeiro. The precipitation data are available at every hour but only for the period from 00:00 UTC 20 February 2010 to 00:00 21 February 2010. General information about these weather stations is shown in Table 2 and locations in Fig. 1 with the corresponding numbers.

We have calculated the following error measures (Keyser and Anthes, 1997; Pielke, 2002): $\phi_{i}$ and $\phi_{i, \text { obs }}$, are individually modelled and observed data in the same grid cell, respectively, $\phi_{0}$ and $\phi_{0, \mathrm{obs}}$ the average of $\phi_{i}$ and $\phi_{i, \mathrm{obs}}$, and $N$ the number of observations. Then,

$\phi^{\prime}=\phi_{i}-\phi_{i, \mathrm{obs}}$

is the deviation between an individual value and the observation. The Bias is given by:

Bias $=\frac{1}{N} \sum_{i=1}^{N} \phi^{\prime}$

The root mean square error is,

$E=\left[\frac{\sum_{i=1}^{n}\left(\phi_{i}-\phi_{i, \mathrm{obs}}\right)^{2}}{N}\right]^{1 / 2}$

and the standard deviation of the error is,

$\mathrm{STDE}=\left[\frac{1}{N} \sum_{i=1}^{n}\left(\phi_{i}^{\prime}-\frac{1}{N} \sum_{i=1}^{n} \phi_{i}^{\prime}\right)\right]^{1 / 2}$

the root mean square, after the removal of a constant bias that can be related to inaccuracy in the specification of the initial and boundary conditions, is given by,

$E_{\mathrm{UB}}=\left[\frac{\sum_{i=1}^{n}\left[\left(\phi_{i}-\phi_{0}\right)-\left(\phi_{i, \mathrm{obs}}-\phi_{0, \mathrm{obs}}\right)\right]^{2}}{N}\right]^{1 / 2}$

\footnotetext{
${ }^{2}$ http://www.meteo.pt
} 


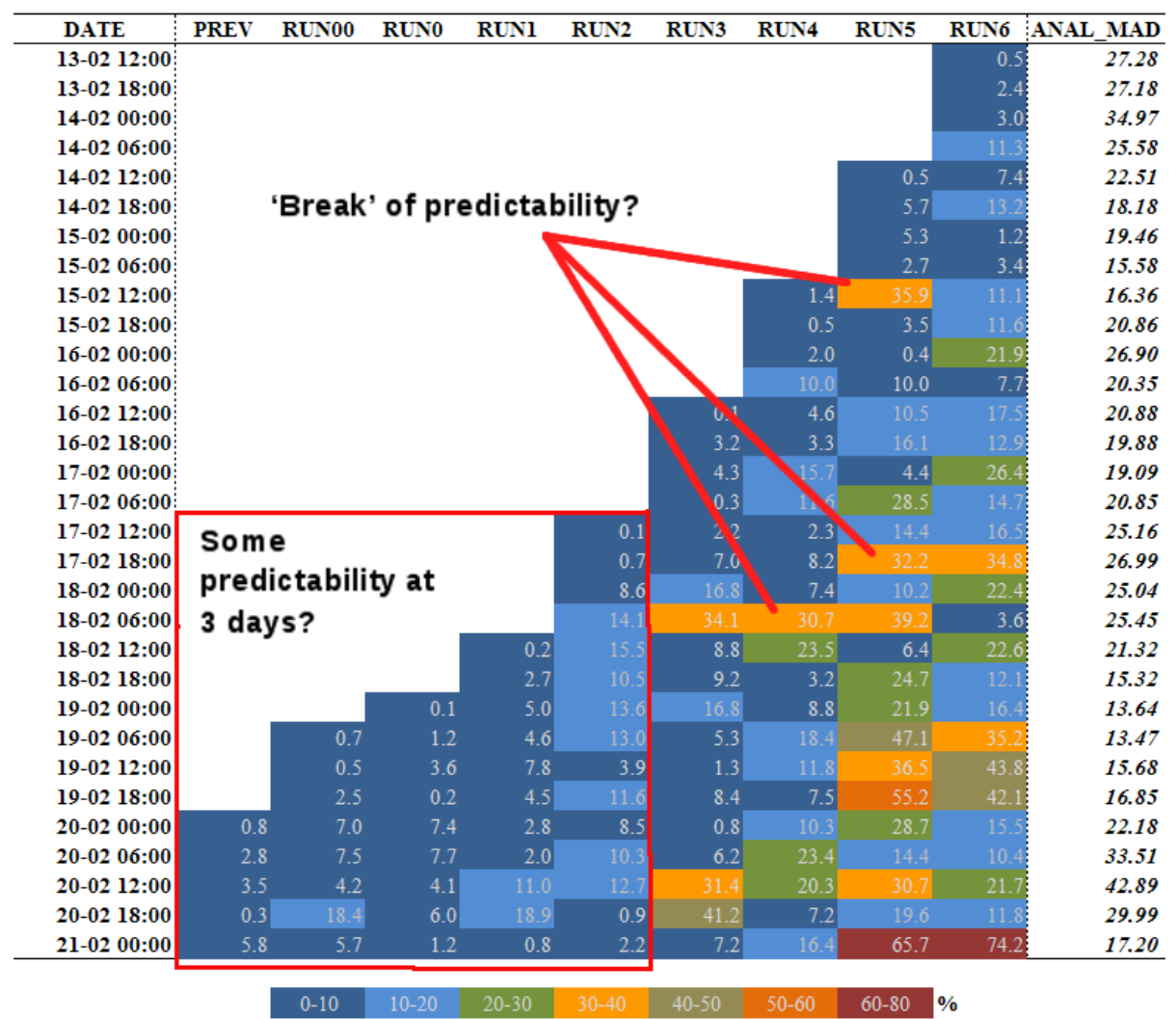

Fig. 3. Difference (\%) between area-averaged precipitable water in the GFS forecast and analysis for a domain covering Madeira Island. GFS forecasts start from day 13 (Run6) until day 20 (RunPrev).

and both, the standard deviation for the modelled data,

$S=\left[\frac{\sum_{i=1}^{n}\left(\phi_{i}-\phi_{0}\right)^{2}}{N}\right]^{1 / 2}$

and observed data,

$S_{\mathrm{obs}}=\left[\frac{\sum_{i=1}^{n}\left(\phi_{i, \mathrm{obs}}-\phi_{0, \mathrm{obs}}\right)^{2}}{N}\right]^{1 / 2}$

We consider that the model skill is high when the following criteria are verified,

$-S \approx S_{\mathrm{obs}}$

$-E<S_{\text {obs }}$

- $E_{\mathrm{UB}}<S_{\mathrm{obs}}$

$-\operatorname{STDE}^{2} \sim E^{2} \Longleftrightarrow \operatorname{Bias}^{2} \ll E^{2}$

\section{Results and discussion}

\subsection{GFS and WRF event predictability}

The precipitable water forecasted by the GFS was compared to that present in the GFS analyses for the available analysis time slices, between the 13 and the 21 February. Figure 3 shows the percentage difference between the different GFS forecast runs, starting at different lag times, and the GFS analysis, relative to the analyses at the same time. There appears to be a breaking on the GFS predictability for Run3 to Run6 as indicated by errors greaters than $30 \%$. This happens at different times along the forecast period. For RunPrev, Run00, Run0, Run1 and Run2, the predictability seems reasonable. Also for the end of the period, high errors are observed for GFS runs initialized from day 13 ( 7 days before the event) to day 16 (4 days before the event). We may conclude that WRF boundary conditions supplied by the GFS forecast show same predictability only from three days before the event.

Since there are considerable errors in the forecast runs with longer time length, it is plausible that the precipitable water amount present in Run6 through Run3 is not associated with the weather system responsible for the water that 

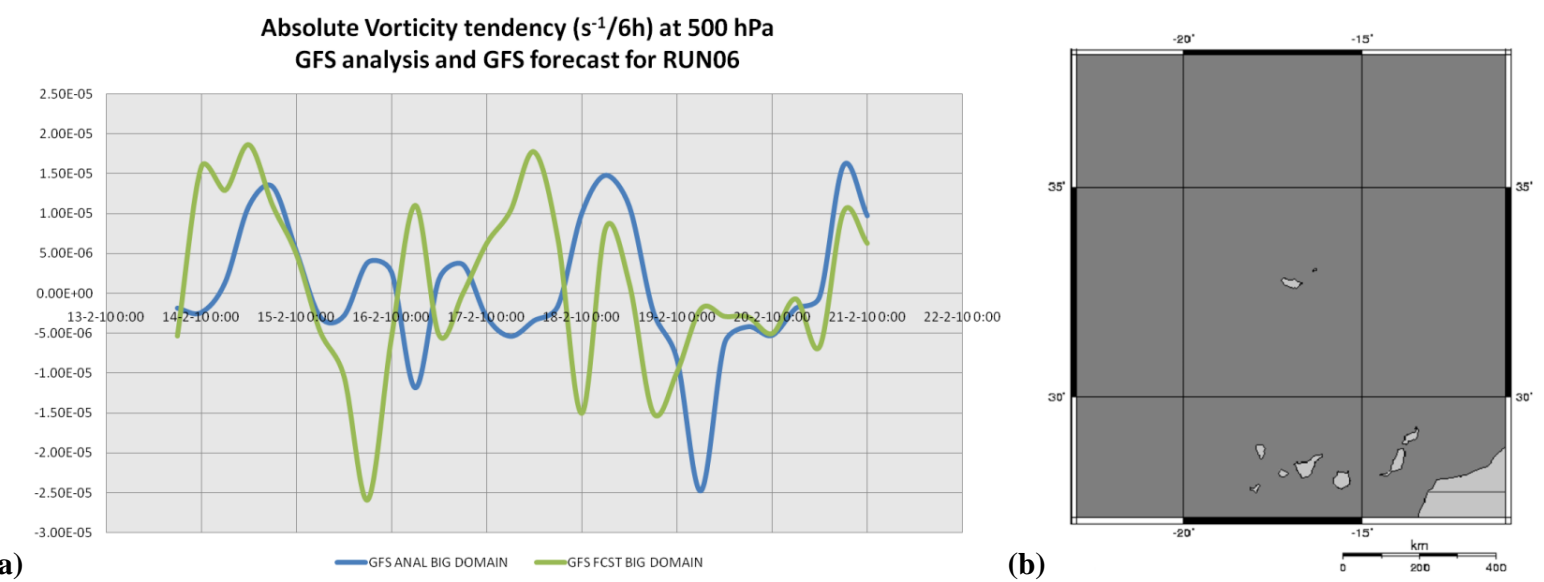

Fig. 4. (a) Area averaged absolute vorticity tendency, at the $500 \mathrm{hPa}$ isobaric surface, for the GFS analysis (blue) and forecast (green). The area considered is shown in (b).

reached the soil on 20 February. The fact that this signal with 7 days is present in Run5 and Run6 may be connected to the synoptic frequency of the weather systems.

To further verify the previous statement, we have calculated the area-averaged absolute vorticity tendency at the $500 \mathrm{hPa}$ isobaric surface, for the GFS analysis and forecast, as shown in Fig. 4a. This has been done for a large area shown in Fig. 4b. It can be seen that, although both curves are in phase during the event, they are out of phase during the days preceding the event. This reinforces the loss of predictability evident in the GFS forecast from day 7 to day 3 before the event, as shown in Fig. 3.

The presented results complement the analysis already referred by Grumm (2010), which stated that the ensemble system of the NCEP GFS model has predicted synoptic conditions associated with the precipitation event studied here, up to 3 days in advance.

\subsection{Model results sensitivity to static features, resolution, cumulus parameterizations}

\subsubsection{Surface analysis}

Here we are interested only in the forecast runs for the day of the event because this is where predicted precipitation was similar to that observed. The runs under inspection are forced by the same GFS forecast fields, namely the control forecast (RunPrev), Run8 (the cumulus parameterization remain active), without topography (TopoOff) and Run7. The last two simulations used active cumulus parameterization over domain D2 and no cumulus parameterization over domain D3.

Daily precipitation was calculated for all these runs and compared to that of the run performed by the model driven by the GFS analysis fields starting at 00:00 UTC on 20 February. Considering the domain D2 (see Fig. 5), the RunPrev simulation overestimates the area-averaged daily precipitation when compared to RunAnal (i.e. forced by the reanalysis fields). This happens for all areas used for the spatial average. If the cumulus parameterization is turned on (in Run8, RunPrev and RunAnal), the southern part of the island shows the highest area-averaged precipitation of around $200 \mathrm{~mm}$. However, explicity resolving convective precipitation in domain D3 (no cumulus parameterization in Run7), gives similar amounts of averaged daily precipitation considering all the island area and the southern and northern coast, over domain D2. Also, precipitation explicitly resolved in domain D3 influences the amount of area-averaged daily accumulated precipitation over the whole Island and below the $800 \mathrm{~m}$ for domain D2. The differences between both are enhanced in this case (see Fig. 5b).

These differences are higher for Run7 and Run8, where the two-way nesting is active. A similar analysis for domain D3 is shown in Fig. 6. Area-averaged precipitation for domain D3 is similar to that simulated in domain D2 when all altitudes are considered (Figs. 5a and 6a). However, precipitation differences between all land points and those at altitudes lower than $800 \mathrm{~m}$ are considerable, particularly for Run7.

The impact of the cumulus parameterization used in domain D3 or the precipitation results in domain D2 may be also observed in Fig. 7, which shows the percentage of total daily precipitation explained by convective precipitation, for locations below $800 \mathrm{~m}$. Although the simulations without topography and Run7 have the cumulus parameterization active on domain D2, the fact that on their domain D3 this parameterization is turned off, makes the contribution of the convective rain to the overall precipitation nearly zero on domain D2 for both simulations. For simulations with active cumulus parameterization in all domains, the convective contribution for total rain is higher over the southern coast than over the northern coast. Higher values are found for domain $\mathrm{D} 2$, when the model is driven by the analyzed GFS fields. 


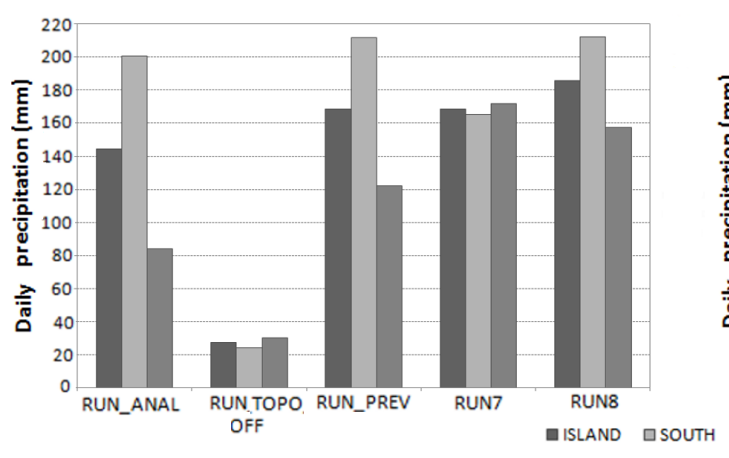

a)

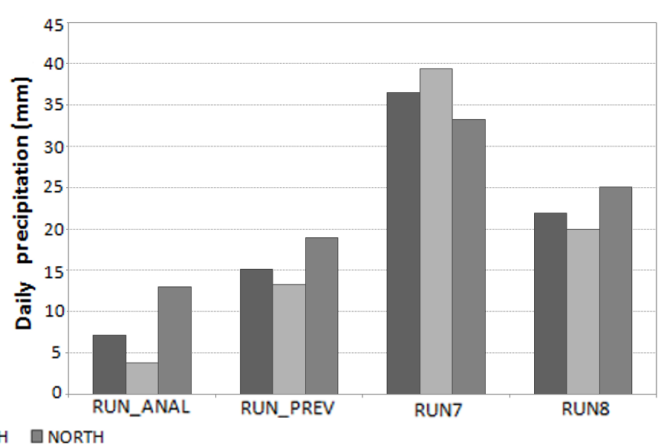

b)

Fig. 5. (a) Daily precipitation, averaged over the whole Madeira Island and its southern and northern coasts, for domain D2, and (b) daily precipitation averaged for locations at altitudes lower than $800 \mathrm{~m}$, for domain D2.

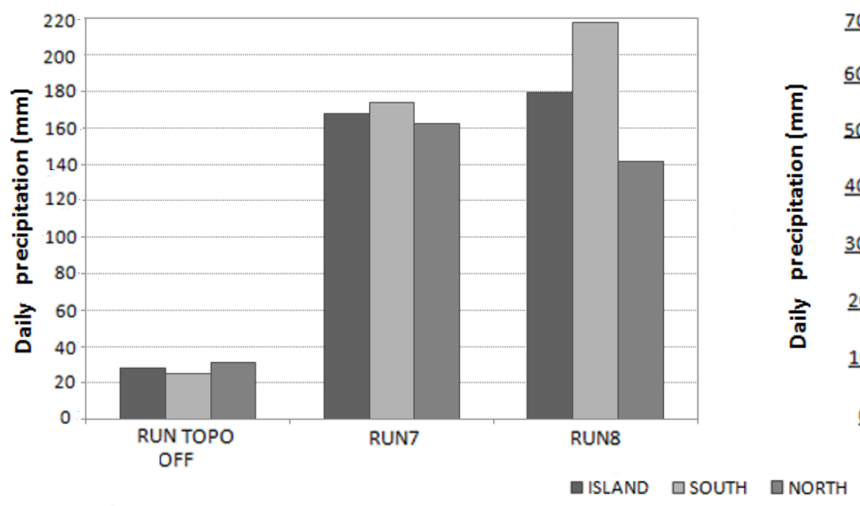

a)

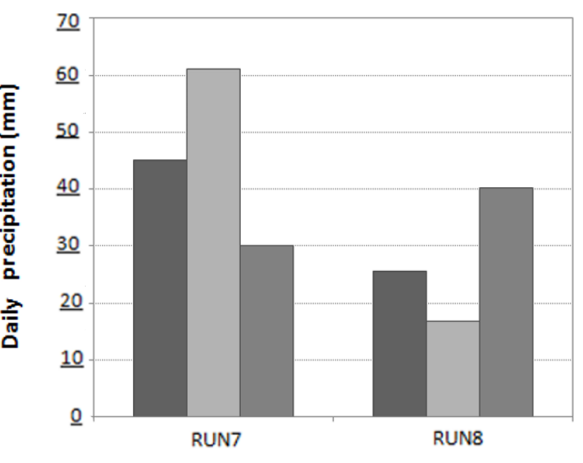

b)

Fig. 6. (a) Daily precipitation, averaged over the whole Madeira Island and its southern and northern coasts, for domain D3, and (b) daily precipitation averaged for locations at altitudes lower than $800 \mathrm{~m}$, for domain D3.

Figure 8 shows the temporal evolution of hourly precipitation averaged over the northern and southern coasts. For the northern coast, maximum precipitation is observed one hour earlier in all simulations when compared with the simulations forced by the GFS analyses. Without topography the maximum appears three hours earlier, but the amount is not significant showing that topography strongly influences precipitation. Over the southern coast, all runs present two maximum precipitation intensities, except for RunAnal. This occurs before and after the precipitation maxima simulated in the northern coast.

\subsubsection{Vertical profiles}

During the period under analysis, the synoptic situation over Madeira Island shows a rapid transition between high and low pressure systems (see Fig. 9). Between the 19 and 20 February, the island was under a surface weak horizontal pressure gradient, in between a through on its right side and a crest on its left side, at the $500 \mathrm{hPa}$, and two depressions near the Labrador Sea. On the 20 February, these two depressions deepened and moved westwards, forming a trough at mean sea level with a high on its right side. The advection of these low pressure systems to the west imposed a western flux over the region on the 21 February.

Local analysis of precipitation is dependent on the horizontal model resolution, as supported by the above results. Having this fact in mind, the following discussion on vertical profiles is focused only on WRF runs with three nested domains, namely Run7, Run8 and TopoOff.

Compared to other studies which evaluated the orographic influence on surface precipitation (ex., Garvert et al., 2005; Colle et al., 2008), the simulation of this event shows some particularities in the sense that Madeira Island may be regarded as a singularity disturbing the synoptic flow, as in wind tunnel experiments. Nevertheless, similar model sensitivity studies performed by Colle et al. (2008) show an enhancement of local precipitation over the windward side of the barrier and less precipitation on their lee side due to the subsidence associated to the gravity waves. The mountain 


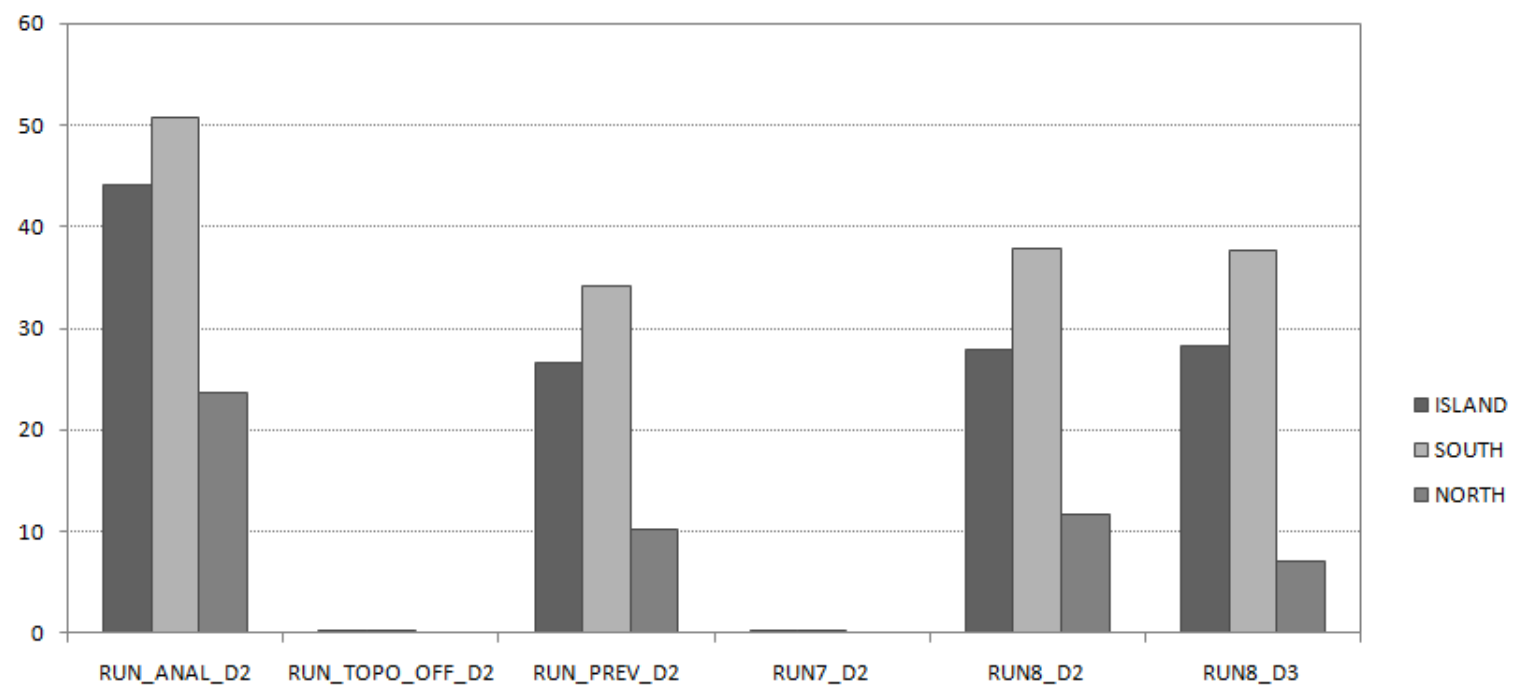

Fig. 7. Percentage of total daily precipitation explained by convective precipitation for locations below $800 \mathrm{~m}$.

chain of Madeira Island is forcing the air mass to climb the windward slope, capturing moisture on the gravity waves induced by the mountain crest located perpendicular to the main flow. These narrow gravity waves, with a width of around $30 \mathrm{~km}$, produce a subsidence region on the lee side of the mountain. This is clearly evident in Fig. 10, which shows vertical-meridional cross sections at $16.9^{\circ} \mathrm{W}$, for equivalent potential temperature, relative humidity and wind vectors (based on the meridional and vertical components) (the cross section is shown in Fig. 1) at three instants (06:00 UTC, 12:00 UTC and 18:00 UTC) over the third domain of Run8 and Run TopoOff.

Results of Run7 are not shown since they are similar to those of Run8. For Run8, at 06:00 and 12:00 UTC, the atmosphere had a high relative humidity (between 80 and $100 \%$ ) up to $5 \mathrm{~km}$ heigh, whereas before (not shown) it was much drier. It is also evident a cold and dry air intrusion from the upper troposphere reaching the northern slopes at the surface persisted until the end of the day. This intrusion is associated with subsidence induced by orographicgenerated gravity waves. At 18:00 UTC, the atmosphere became much drier, particularly at about $5 \mathrm{~km}$, with relative humidity reaching 10-20\% over a wide area. At 06:00 UTC the atmospheric instability near surface was greater than at noon and at 18:00. The fact that the static atmospheric stability enhanced through the day, may favour microphysics processes rather than convective structures in the model. Gravity waves and the upper-tropospheric cold and dry intrusion were completely absent in the TopoOff run. As for Run8, the lower and middle troposphere was also nearly saturated in the run TopoOff. Figure 11 shows, for Run8 and TopoOff, the time evolution of the vertical profiles of the equivalent potential temperature, relative humidity and horizontal wind at three locations: Funchal, in the windward slope at sea level, Areeiro, near the top and S. Jorge on the lee side.

It is evident that the passage of an occlusion front occurred at the three locations. At the beginning of the simulation, the wind is weak at surface at the three locations with drier and colder conditions than at at midday. At S. Jorge (lee side) there is less moisture than at Funchal (windward side). All locations show cold pools near the surface at the beginning and end of the day. Hotter and humid air has advected from the South and the southwestern sectors. The main flow remains from the west after 18:00 UTC at Funchal and S. Jorge, with a weak meridional component at Areeiro (crest). The rotation of the wind is observed from surface up to $4 \mathrm{~km}$. This lower tropospheric wind rotation is the result of the rotation felt at higher levels (between 5 and $10 \mathrm{~km}$, winds shift from northwestern to southwestern sectors). It may also be observed that two different air masses have vertical expression from the surface up to $200 \mathrm{hPa}$, between 14:00 UTC and 21:00 UTC. Several aspects are occurring before noon. As seen in Fig. 4, there is a positive vorticity tendency which indicates an intensification of cyclonic pattern. The advection of hot and humid air from the southern sectors encounters cold and dry air in the middle troposphere, forcing the moisture air to ascend to higher levels (this may be observed in Fig. 11, at all locations, considering or not the presence of the terrain height and land use of Madeira Island).

Figure 12 shows the time evolution of the equivalent potential temperature lapse rate, for each of the three locations under analysis, and for both Run8 and TopoOff. Instability is present near the surface during most of the day, particularly at Funchal for Run8. For the other locations regarding Run8, this instability is not as strong. Run TopoOff shows less instability for all stations, and at higher altitudes $(1 \mathrm{~km})$, 

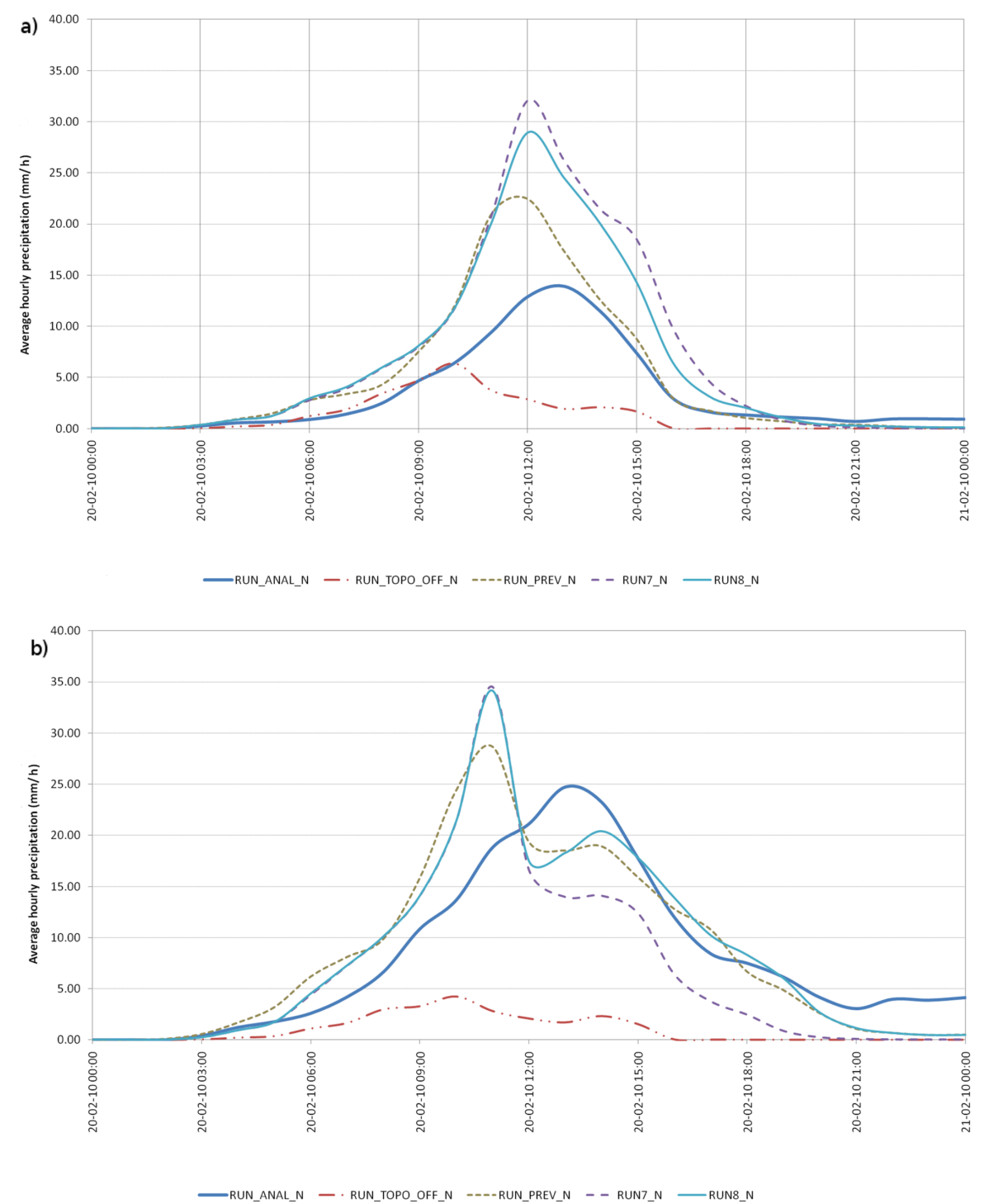

Fig. 8. Time evolution of simulated area-averaged hourly precipitation over the entire (a) northern coast and (b) southern coast, over domain D2.

revealing more stable conditions near the surface, this being consistent with smaller precipitation amounts.

Another factor which may have contributed to the event was a sea surface temperature (SST) positive anomaly to the south of Madeira (Fig. 13). The predominantly southwestern flux in the lower and middle troposphere was able to capture high quantities of water vapor creating necessary but not sufficient conditions for the occurrence of intense precipitation. The latter were associated to the presence of topography in Madeira.

\subsubsection{Soil variables}

During this event, the flashfloods and landslides caused several human losses and 250 millions of Euros were needed for the reconstruction of the damaged infrastructure ${ }^{3}$. Therefore, the analysis of soil propertied namely surface runoff and soil moisture content is of relevance.

Figure 14 shows the time evolution of precipitation (convective and grid-scale), runoff and soil moisture content at

\footnotetext{
${ }^{3}$ http://reliefweb.int/node/375516
} 

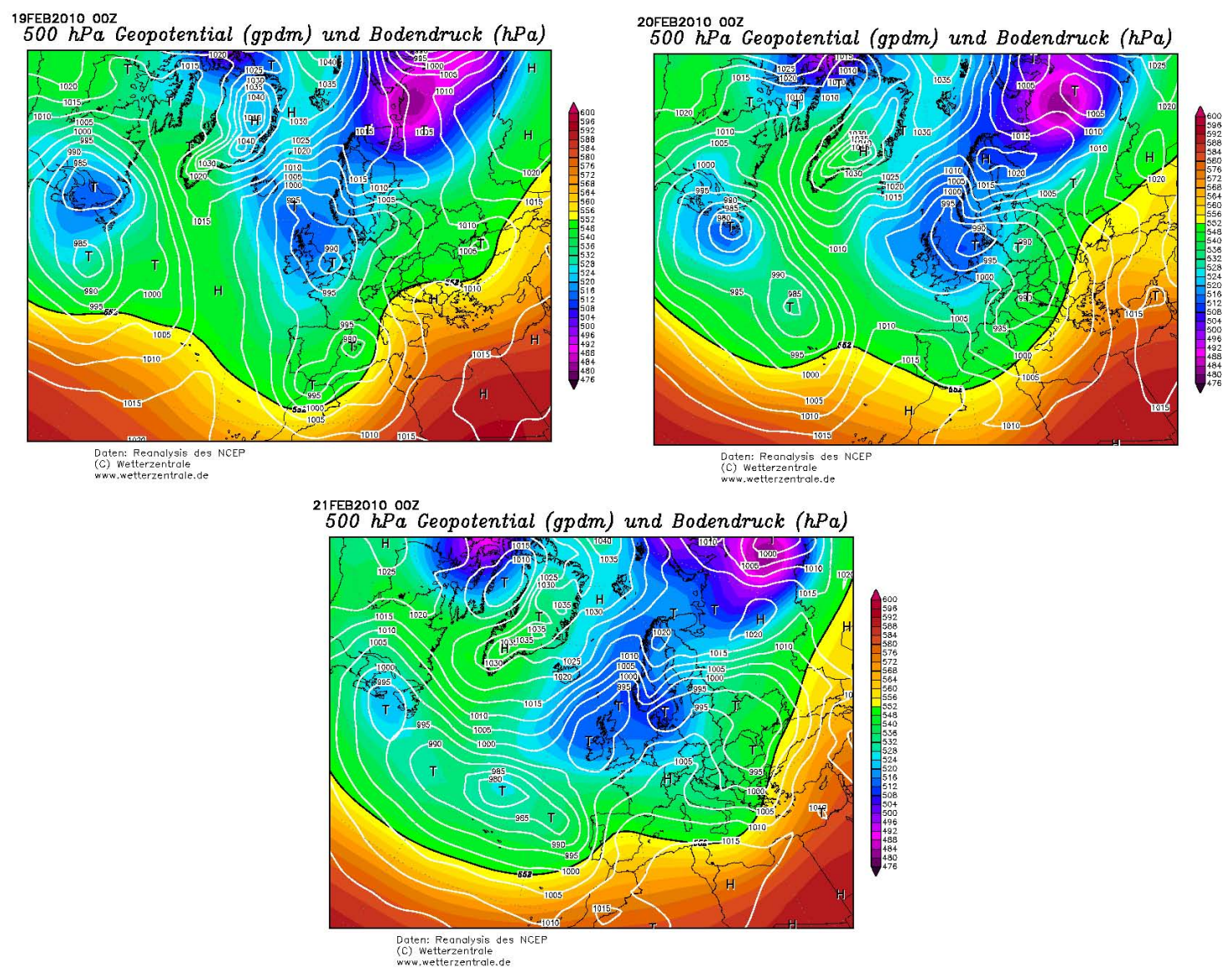

Fig. 9. Geopotential height at $500 \mathrm{hPa}$ and mean sea level pressure at 00:00 UTC between the 19 and 21 February 2010 (http://www.osdpd. noaa.gov/ml/ocean/sst/anomaly_2010.html).

Funchal for the forecast started at 00:00 UTC of 13 February (Run6) (left panel) and at 00:00 UTC of 20 February (right panel). To evaluate the soil's moisture behaviour after the event, which occurred at 11:00 UTC on 20 February, results for RunPrev are shown until 12:00 UTC on 23 February. The model simulates well the time and amplitude of the extreme rainfall event. Interestingly, forecasts which started after 13 February show little predictability of the event. This loss of predictability has been addressed in Sect. 3.1. Convective precipitation contributes little to total precipitation. Surface runoff responds promptly to precipitation with a lag of a few hours but their maxima occur simultaneously. For Run6, precipitation which occurred on 13 and 14 February increased the soil moisture content which remained high (above $0.3 \mathrm{~m}^{3} \mathrm{~m}^{-3}$ ) until the event at 11:00 UTC of 20 February. After the event, the soil remained nearly saturated (approximately $0.4 \mathrm{~m}^{3} \mathrm{~m}^{-3}$ ) for the following three days, as shown for RunPrev (right panel).

\subsection{Model skills on simulating precipitation}

In order to validate local precipitation simulated by the model, we have compared it to precipitation observed at six meteorological stations (shown in Fig. 1). This has been done for 20 February, the day of the event.

Figure 15, shows daily total precipitation simulated and observed at Funchal, for the day of the event. Only runs which started $12 \mathrm{~h}$ before the peak of the event show reasonable values. This is also true (not shown) for other stations.

Figure 16 shows hourly precipitation simulated and observed at the six locations, for two simulations with $1 \mathrm{~km}$ horizontal resolution, namely, Run7 and Run8. These runs differ only on the cumulus parameterization in domain D3 (see Table 1).

The results show that, in general, the amplitude and phase of precipitation in these runs are well simulated. Both runs simulated similar precipitation, with Run7 showing slightly better results when compared to observations. For example, at Funchal, where the tragedy had its greatest impact, Run8 simulated unrealistically high precipitation after the observed 

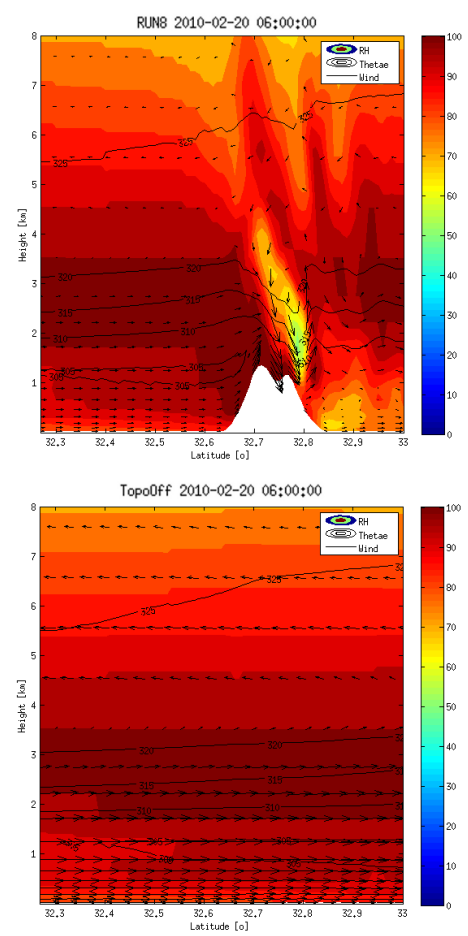

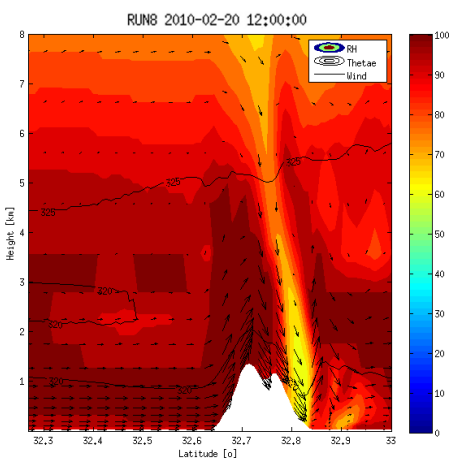

Topolff 2010-02-20 12:00:00

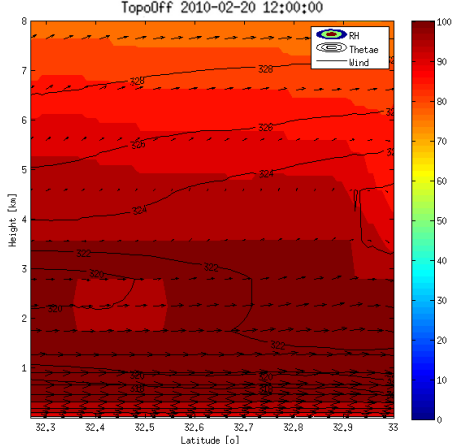

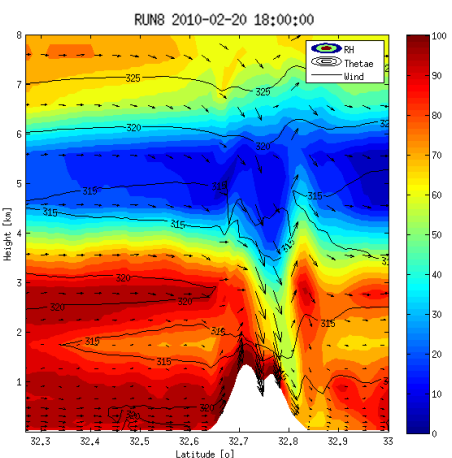

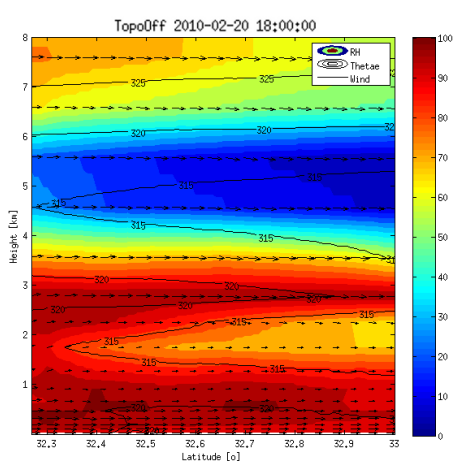

Fig. 10. Vertical Cross Sections of equivalent potential temperature (K), relative humidity $(\%)$ and wind vectors $(v$ and $w$ components $\left.\mathrm{m} \mathrm{s}^{-1}\right)$.
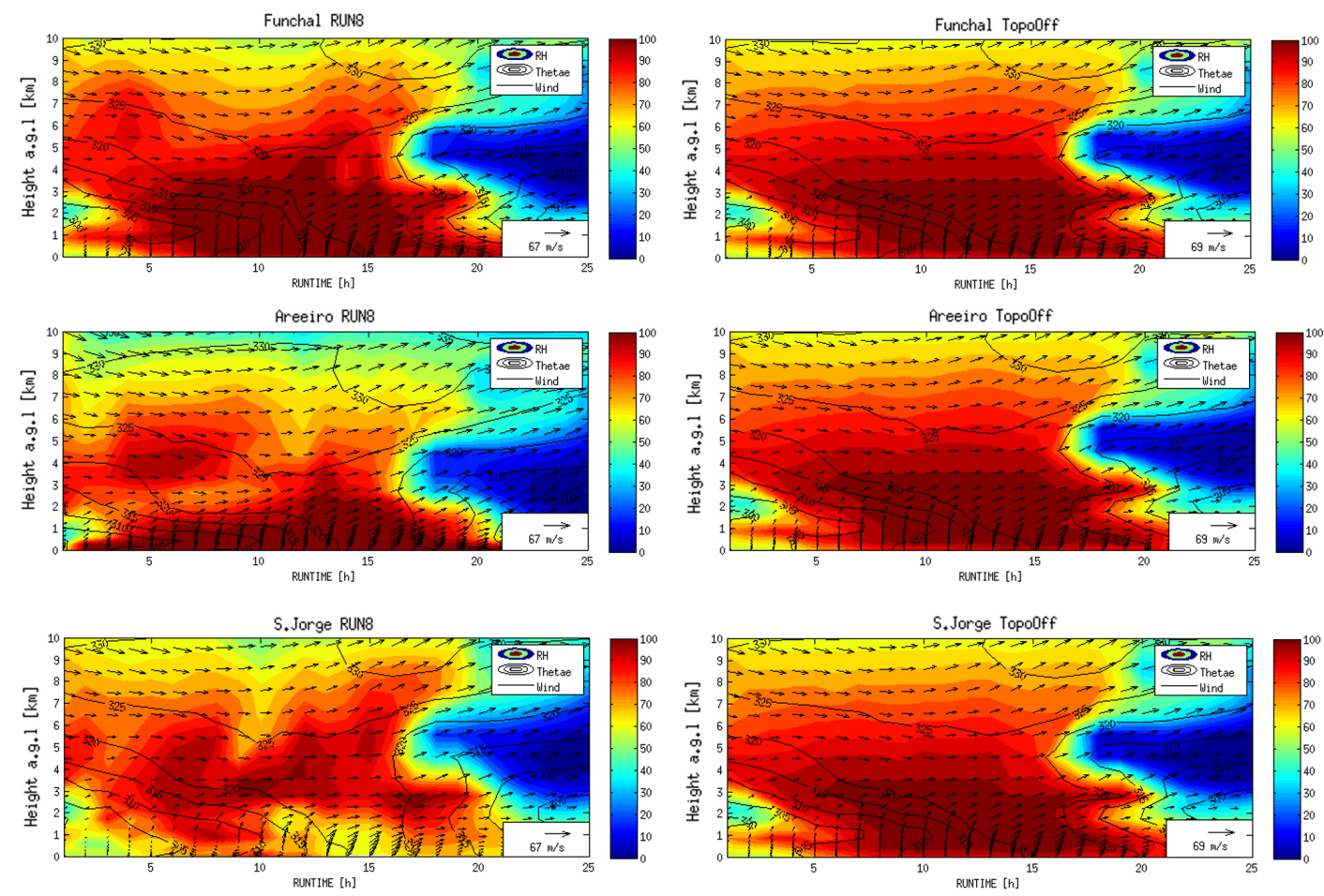

Fig. 11. Time evolution of equivalent potential temperature, relative humidity and horizontal wind over Funchal (windward), Areeiro (crest) and S. Jorge (lee side). 

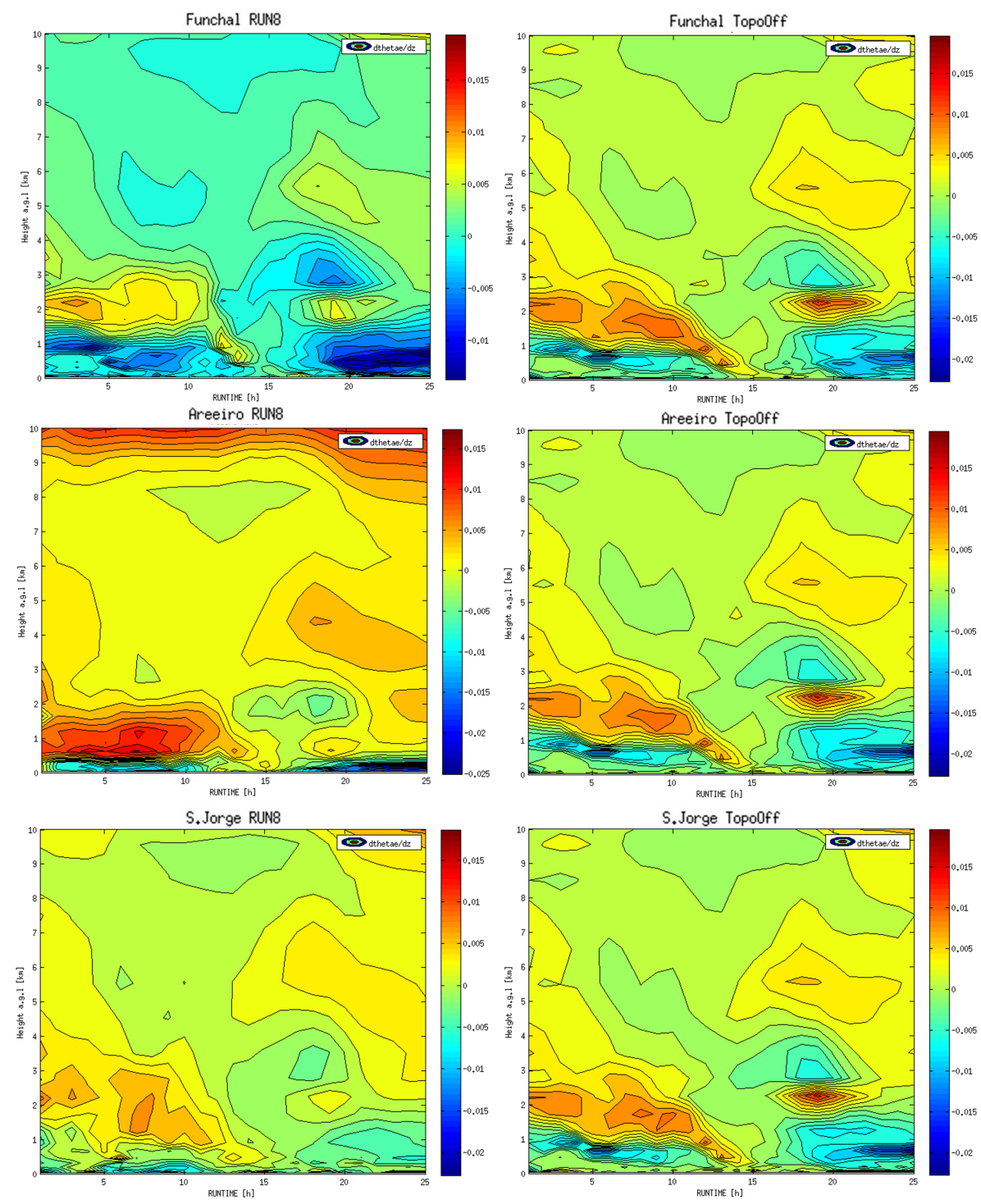

Fig. 12. Time evolution of equivalent potential temperature lapse rate over Funchal (windward), Areeiro (crest) and S. Jorge (lee side).

NOAA/NESDIS SST Anomaly (degrees C), 2/18/2010

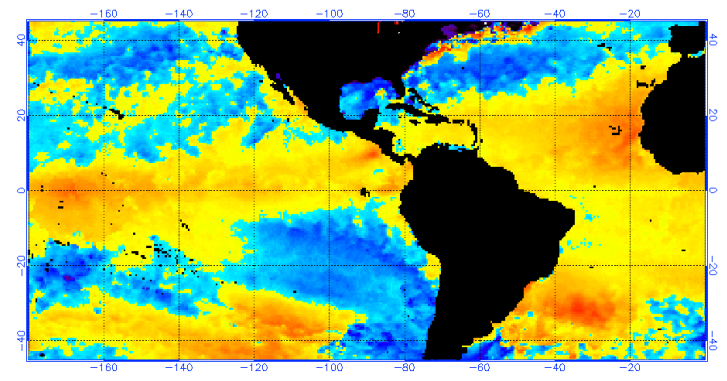

NOAA/NESDIS SST Anomaly (degrees C), 2/22/2010

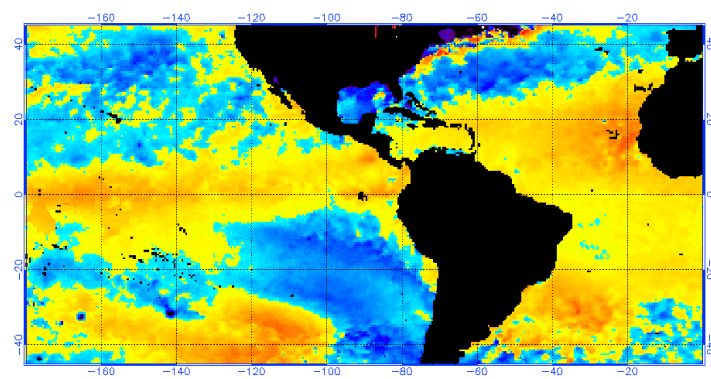

\begin{tabular}{l|l|l|l|l|l|l|l|l|l|lll}
0.00 & 0.50 & 1.00 & 1.50 & 2.00 & 2.50 & 3.00 & 3.50 & 4.00 & 4.50 & 5.00 \\
\hline
\end{tabular}

Fig. 13. SST anomalies for 18 and 22 February 2010. 

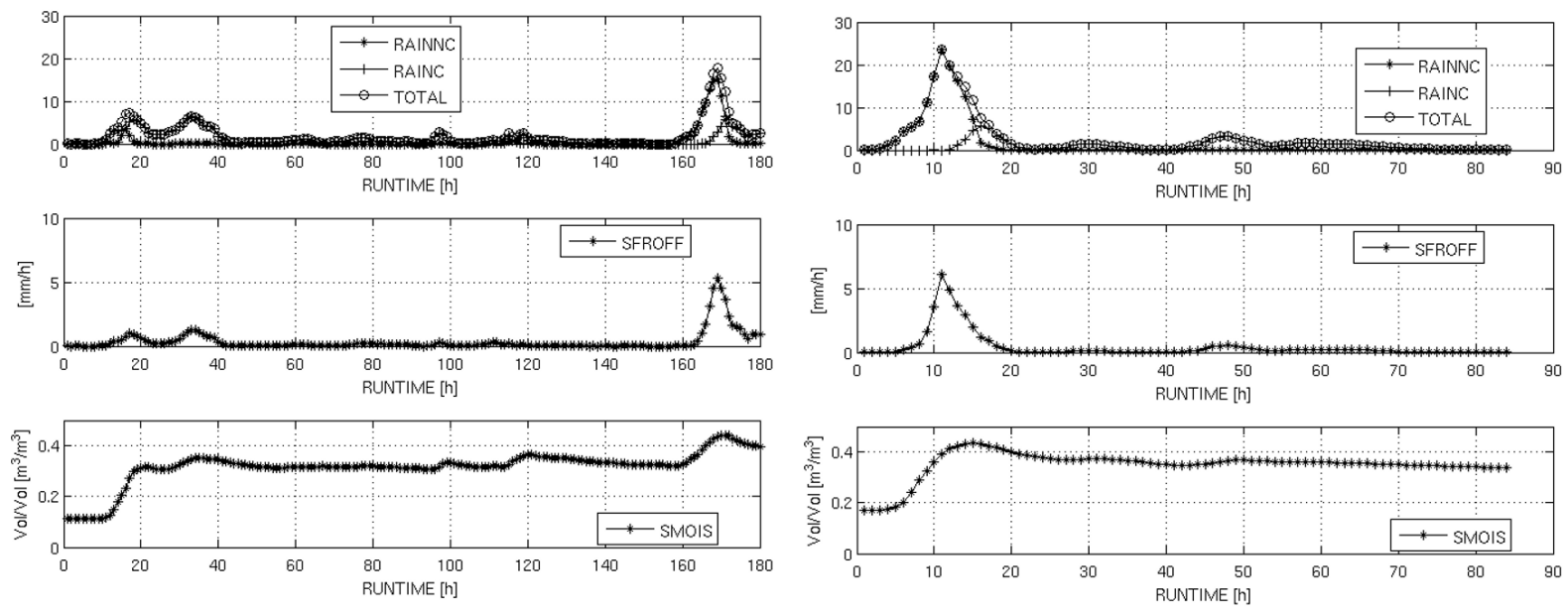

Fig. 14. Simulated hourly precipitation (convective=RAINC and grid-scale=RAINNC), water runoff and soil moisture content at Funchal. Left panel: Run6 (starting at 12:00 UTC, 13 February to 00:00 UTC 21 February). Right panel: RunPrev (starting at 00:00 20 February to 12:00 UTC 23 February).

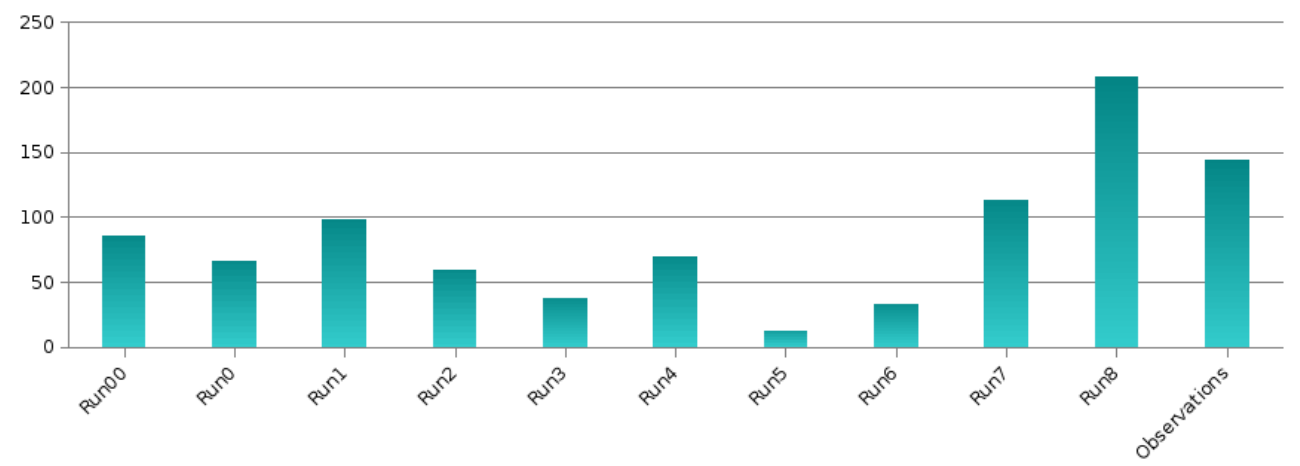

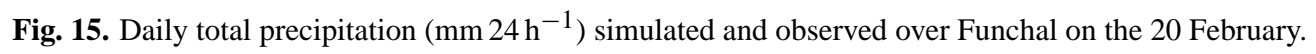

peak in the afternoon. The greatest discrepancies between model and observations are observed for Ponta do Pargo. This may be due to its location where the terrain is very steep near the sea. For this station, the difference between the real and model's altitude is highest $(300 \mathrm{~m})$. Due to the orography nature of precipitation, this may explain the differences between the observed and simulated rainfall.

Table 3 shows these errors for each location, for domain D2, for all runs except Run7 and Run8. In these runs, the highest horizontal resolution is $5 \mathrm{~km}$ for domain D2. Table 4 shows the same errors for the high resolutions simulations, namely Run7 and Run8. In general, the errors are smaller for Run7 and Run8, indicating that the horizontal resolution is important in simulating local precipitation. All simulations underestimate precipitation (negative bias), with Run8 showing the best result. Average local precipitation is not statistically different between Run7, Run8, RunPrev and observations. Correlation coefficients greater than 0.25 are statistically different from zero at the $1 \%$ significant level.

\section{Concluding remarks}

The main objective of this work has been to investigate the nature and predictability of the precipitation extreme event which occurred at Madeira Island, on 20 February 2010. To achieve this, several simulations have been performed and the model skill was evaluated. To evaluate predictability, some of these simulations started from initial conditions from seven days to $12 \mathrm{~h}$ before the peak of the event (approximately at 11:00 UTC of 20 February 2010). We also evaluated the quality of the initial and boundary conditions of these simulations by comparing the GFS forecast, (used here to force the model) with the GFS analysis. In particular, we also evaluated the sensitivity of simulated precipitation to the topography of the island, horizontal resolution and cumulus parameterization.

The main conclusions can be summarized as follows, answering the addressed questions asked in the Introduction: 
Table 3. Error Analysis over domain D2 ( $R$ is the spatial correlation between simulated and observed precipitation).

\begin{tabular}{lrrrrrrrrrr}
\hline Domain D2 & Run00 & Run0 & Run1 & Run2 & Run3 & Run4 & Run5 & Run6 & RunPrev & RunAnal \\
\hline Bias & 3.81 & -3.24 & -3.81 & -4.4 & -4.96 & -5.05 & -7.41 & -7.49 & -1.68 & -3.08 \\
$E$ & 9.37 & 9.01 & 9.43 & 10.51 & 11.68 & 12.07 & 14.19 & 13.70 & 6.96 & 9.67 \\
STDE & 8.19 & 8.08 & 8.18 & 8.98 & 10.23 & 10.47 & 11.63 & 11.19 & 6.11 & 8.49 \\
$S / S_{\text {obs }}$ & 0.78 & 0.80 & 0.56 & 0.57 & 0.50 & 0.49 & 0.05 & 0.13 & 0.98 & 0.64 \\
$E / S_{\text {obs }}$ & 0.80 & 0.83 & 0.75 & 0.79 & 0.92 & 0.94 & 1.08 & 1.05 & 0.70 & 0.80 \\
$E_{\mathrm{UB}} / S_{\text {obs }}$ & 0.73 & 0.78 & 0.74 & 0.76 & 0.91 & 0.90 & 1.00 & 0.97 & 0.64 & 0.76 \\
$N$ & & & & & & 131 & & & & \\
$R$ & 0.79 & 0.8 & 0.76 & 0.70 & 0.45 & 0.52 & -0.17 & 0.29 & 0.90 & 0.75 \\
\hline
\end{tabular}

t-student $95 \%$

(Are model and observed precipitation means different?)

\begin{tabular}{llllllllll} 
Yes & Yes & Yes & Yes & Yes & Yes & Yes & Yes & No & Yes \\
\hline
\end{tabular}
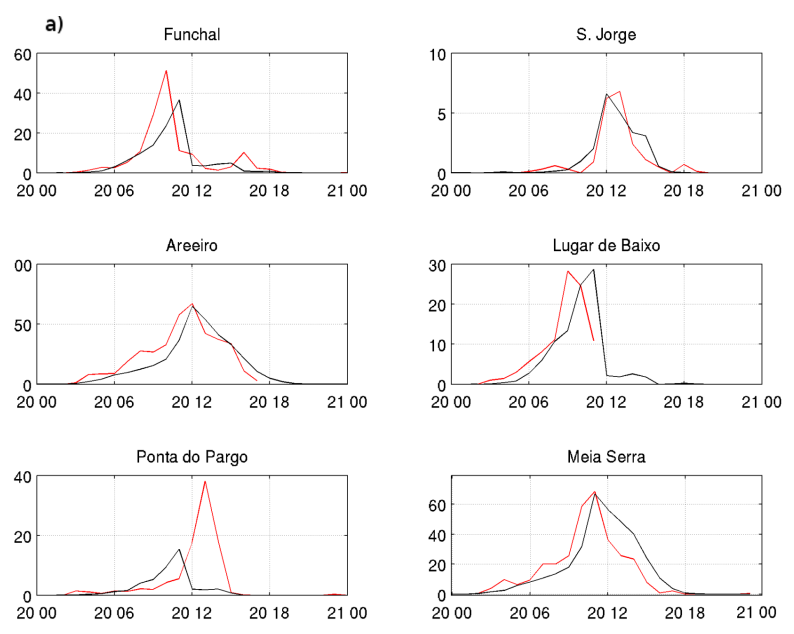

\section{b)}
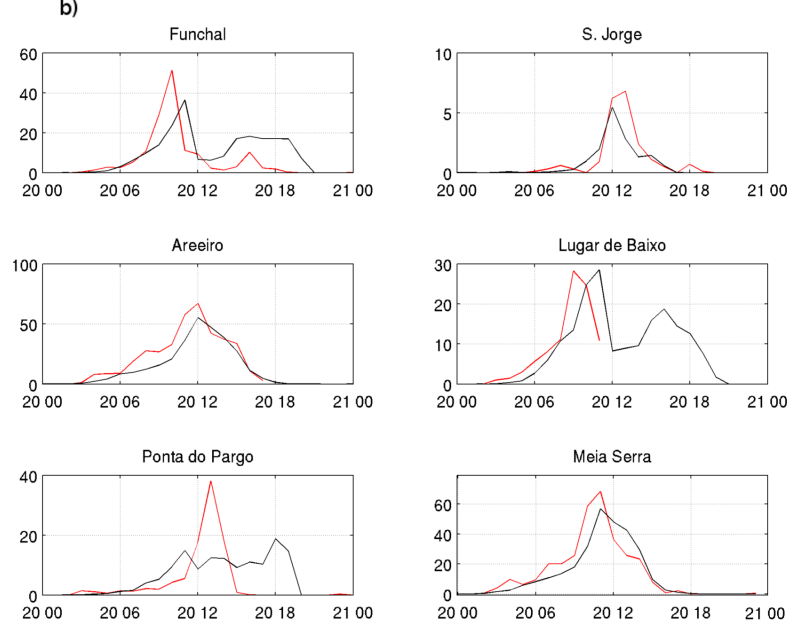

Fig. 16. Measured (red) and simulated (black) hourly precipitation obtained for all stations for (a) Run7 and (b) Run8, over domain D3.
Table 4. Error Analysis over domain D3 ( $R$ is the spatial correlation between simulated and observed precipitation).

\begin{tabular}{lcc}
\hline Domain D3 & Run7 & Run8 \\
\hline Bias & -0.89 & -0.46 \\
$E$ & 7.11 & 6.99 \\
$\mathrm{STDE}$ & 6.97 & 6.62 \\
$S / S_{\text {obs }}$ & 1.07 & 0.99 \\
$E / S_{\text {obs }}$ & 0.61 & 0.67 \\
$E_{\mathrm{UB}} / S_{\text {obs }}$ & 0.62 & 0.62 \\
$N$ & 131 & 131 \\
$R$ & 0.84 & 0.84 \\
\hline t-student 95\% & & \\
(Are model and observed & & \\
precipitation means different?) & No & No \\
\hline
\end{tabular}

1. Was the event predictable?

There was some predictability up to three days before the event. This was mainly dictated by the quality of initial and boundary conditions supplied by the GFS global forecast.

2. If yes:

How long before its occurrence?

Even considering the previous point, daily total precipitation is not well simulated by runs which started more than $12 \mathrm{~h}$ before the peak precipitation.

With maximum precipitations amounts correct?

Without phase errors?

Local precipitation, namely its amplitude and phase, is well simulated only when simulations are initialized $12 \mathrm{~h}$ before the event. 
3. Was its origin synoptic or orographic?

The synoptic pattern on the 20 February 2010 showed positive vorticity tendency and an intensification of a high level through passing through the region. This set the background scenario for wind rotation from northwestern/Western to south/southwestern during the day. After this wind rotation the southern-oriented slope of Madeira acted as a perpendicular barrier to the nearsurface synoptic flux. This air mass had travelled through a vast area of positive SST anomalies in the tropical north Atlantic and became rich in moisture content. On the day of the event, the passage of an occlusion front embedded in this low tropospheric southern flux and a concurrent northern cold flow aloft also contributed to increase instability. However, the main process which transformed the high moisture content of the southern flow was orographic lifting imposed by Madeira topography.

4. What is the sensitivity of the simulations to higher horizontal resolution and cumulus parameterization?

Horizontal resolution is important to simulate local precipitation but not as such to simulated area-averaged precipitation. The choice of using or not using cumulus parameterization is not relevant to simulated precipitation in this particular event. This is because the atmosphere is neutral to stable at the windward side of the mountain inhibiting convection. Upward vertical velocities occurred due to orographic lifting and, therefore, precipitation was generated by the microphysics parameterizations rather than cumulus parameterizations. Finally, the impact of this extreme precipitation event can only be assessed by coupling the simulated surface/soil properties, namely moisture and surface runoff, with hydrological models to evaluate landslide risk.

Acknowledgements. The authors are grateful to the Portuguese Foundation of Science and Technology for the grants supporting Juan Ferreira (SFRH/BD/31465/2006) and João Sousa (SFRH/BD/64515/2009). The authors also gratefully acknowledge Valor Ambiente - Gestão e Administração de Resíduos da Madeira, S.A for the use of Meia Serra weather data.

Edited by: L. Ferraris

Reviewed by: two anonymous referees

\section{References}

Chen, F. and Dudhia, J.: Coupling an advanced landsurface/hydrology model with the Penn State/ NCAR MM5 modeling system. Part I: Model description and implementation, Mon. Weather Rev., 129, 569-585, 2001.

Colle, A. C.: Sensitivity of Orographic Precipitation to Changing Ambient Conditions and Terrain Geometries: An Idealized Modeling Perspective, J. Atmos. Sci., 61, 588-606, 2004.

Colle, B. A., Lin, Y., Medina, S., and Smull, B.: Orographic modification of convection and flow kinematics by the Oregon coastal range and Cascades during IMPROVE-2. Mon. Weather Rev., 136, 3894-3916, 2008.

Costa, M. J., Salgado, R., Santos, D., Levizzani, V., Bortoli, D., Silva, A. M., and Pinto, P.: Modelling of orographic precipitation over Iberia: a springtime case study, Adv. Geosci., 25, 103-110, 2010 ,

http://www.adv-geosci.net/25/103/2010/.

Crosta, G.: Regionalization of rainfall thresholds: an aid to landslide hazard evaluation, Environ. Geol., 35 (2-3) August 1998.

Ferreira, A. P.: Sensibilidade às parametrizações físicas do WRF nas previsões à superfície em Portugal Continental. Relatório de estágio em Meteorologia e Oceanografia Fsica. Universidade de Aveiro, Aveiro-Portugal, 125 pp. http://climetua.fis.ua. pt/publicacoes/Estagio_PauloFerreira.pdf, 2007.

Garvert, M., Colle, B. A., and Mass, C. F.: The 13-14 December IMPROVE event: Part I, Synoptic and mesoscale comparison of the observed structures with a mesoscale model simulation, J. Atmos. Sci., 62, 3474-3492, 2005.

Grell, G. A. and Devenyi, D.: A generalized approach to parameterizing convection com- bining ensemble and data assimilation techniques, Geophys. Res. Lett., 29(14), 1693, 2002.

Grumm, R. H.: The Madeira Island Floods of 20 February 2010, National Weather Service of the United States of America, http: //nws.met.psu.edu/severe/2010/20Feb2010.pdf, 2010.

Hohenegger, C., Walser, A., Wolfgang, L., and Schar, C.: Cloudresolving ensemble simulations of the August 2005 Alpine flood, Q. J. R. Meteorol. Soc., 134, 889-904, 2005.

Hong, S. Y. and Lim, J. O. J.: The WRF Single-Moment 6-Class Microphysics Scheme (WSM6), J. Korean Meteor. Soc., 42, 129-151, 2006.

Janjic, Z. I.: The step-mountain coordinate: physical package, Mon. Weather Rev., 118, 1429-1443, 1990.

Janjic, Z. I.: The surface layer in the NCEP Eta Model. Eleventh Conference on Numerical Weather Prediction, Norfolk, VA, 19-23 August 1996; Amer. Meteor. Soc., Boston, MA, 354-355, 1996.

Janjic, Z. I.: Nonsingular Implementation of the Mellor Yamada Level 2.5 Scheme in the NCEP Meso model, NCEP Office Note,437, 61 pp., 2002.

Keyser, D. and Anthes, R.A.: The applicability of a mixed-layer model of the planetary boundary layer to real-data forecasting, Mon. Weather Rev., 105, 1351-1371, 1977.

Lin, Y. L.: Mesoscale Dynamics, Cambridge University Press, ISBN-13 978-0511-37691-7, 2007.

Mlawer, E. J., Taubman, S. J., Brown, P. D., Iacono, M. J., and Clough, S. A.: Radiative transfer for inhomogeneous atmosphere: RRTM, a validated correlated-k model for the long-wave, J. Geophys. Res., 102(D14), 16663-16682, 1997.

NCEP: The GFS Atmospheric Model. NCEP Office Note 442, 
Global Climate and Weather Modeling Branch, EMC, Cam Springs Maryland, 2003.

Pielke, R. A.: Mesoscale Meteorological Modeling. Academic Pressm San Diego, CA, 2002.

Ray, R. L. and Jacobs, J. M.: Relationships among remotely sensed soil moisture, precipitation and landslide events, Nat. Hazards, 43, 211-222, doi:10.1007/s11069-006-9095-9, 2007.

Skamarock, W. C., Klemp, J. B., Dudhia, J., Gill, J., Barke, D. M., Wang, W., and Powers, J. G.: A description of the Advance Reaserch WRF version. NCAR Technical Note, NCAR/TN468+STR, 88 pp., http://www.britannica.com/EBchecked/topic/ 355699/Madeira-Island http://amsglossary.allenpress.com/ glossary/search?id=precipitable- water1, 2005.
Skamarock, W. C., Klemp, J. B., Dudhia, J., Gill, D. O., Barker, D. M., Duda, M. G., Huang, X.-Yu., Wang, W., and Powers, J. G.: A description of the Advanced Research WRF version 3. NCAR Technical Note, NCAR/TN475+STR, 125 pp., 2008.

Srinivasan, J., Nanjundiah, R. S. and Chakraborty, A.: Impact of Orography on the Simulation of Monsoon Climate in a General Circulation Model, Indian Institute of Science, 2005.

Wallace, J. M. and Hobbs, P.V.: Atmospheric Science: An introductory survey, Academic Press, 1977. 